\title{
Minimal intervention dentistry II: part 7. Minimal intervention in cariology: the role of glass-iono- mer cements in the preservation of tooth structures against caries
}

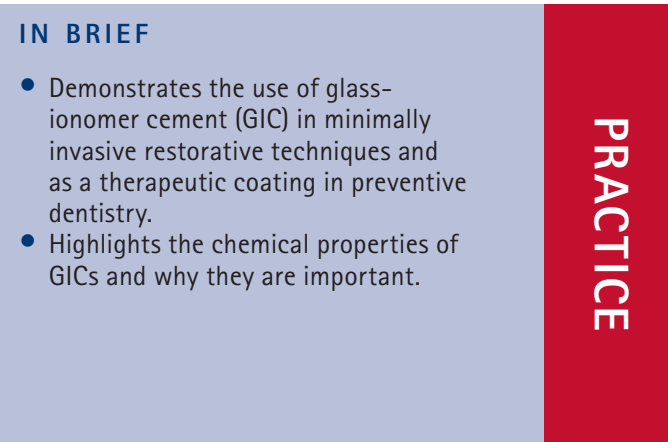

\author{
H. Ngo*1 and S. Opsahl-Vital2,3
}

Glass-ionomer cements (GICs) are essential materials in clinical practice because of their versatility, self-adhesion to enamel and dentine, and good biocompatibility. In addition, being chemically cured, with no shrinkage stress, makes them well suited for minimally invasive restorative techniques. This article looks at some of the clinical situations where the chemical adhesion and high biocompatibility of GIC are important for clinical success: excavation of deep carious lesions, fissure sealing and protection of root surfaces against caries.

The philosophy of minimal intervention (MI) dentistry is gaining popularity around the world; it recognises that caries is a multifactorial, life-style associated condition, which is driven by an unhealthy oral biofilm and an

\begin{tabular}{l} 
MINIMAL INTERVENTION \\
DENTISTRY II \\
\hline 1. Contribution of the operating microscope to \\
dentistry \\
2. Management of caries and periodontal risks \\
in general dental practice \\
3. Management of non-cavitated (initial) \\
occlusal caries lesions - non-invasive \\
approaches through remineralisation and \\
therapeutic sealants \\
4. Minimal intervention techniques of \\
preparation and adhesive restorations. The \\
contribution of the sono-abrasive techniques \\
5. Ultra-conservative approach to the treatment \\
of erosive and abrasive lesions \\
6. Microscope and microsurgical techniques in \\
periodontics \\
7. Minimal intervention in cariology: the \\
role of glass-ionomer cements in the \\
preservation of tooth structures against \\
caries \\
8. Biotherapies for the dental pulp \\
This paper is adapted from: Ngo $\mathrm{H}$, Opsahl-Vital S. Intervention \\
minimale. La place des ciments verre ionomere. Réalités Cliniques \\
2012; 23: 235-242.
\end{tabular}

${ }^{1}$ Faculty of Dentistry, Kuwait University, PO Box 24923 Safat, 13110 Kuwait; ${ }^{2}$ EA2496 Pathologies, Imaging and Biotherapies of the Tooth, Dental School, University Paris Descartes PRES Sorbonne Paris Cité, 92120 Montrouge, France: ${ }^{3} \mathrm{AP}-\mathrm{HP}$ Service Odontologie HUPNVS ${ }^{*}$ Correspondence to: Professor Hien C Ngo

Email: hien.ngo@hsc.edu.kw

\section{Refereed Paper}

Accepted 15 November 2013

DOI: $10.1038 /$ sj.bdj.2014.398

${ }^{\circ}$ British Dental Journal 2014; 216: 561-565 unbalanced oral environment. MI is supported by the following four pillars: individual risk assessment, detection and management of non-cavitated lesions, effective preventive care and minimally invasive restorative techniques. At every stage in the management of caries clinicians should aim for maximum preservation of tooth structures.

This article will focus on the use of glassionomer cement (GIC) in minimally invasive restorative techniques and as a therapeutic coating in preventive dentistry. As a group of materials, GIC is very versatile; examples can be found as restorative materials, cavity liners, luting cements, fissure sealants and therapeutic coatings. ${ }^{1-3}$ This last terminology is used to describe a material that can be painted on susceptible tooth surfaces to form a long lasting coat and provide both physical and chemical protection against caries.

\section{BIOCOMPATIBILITY OF GLASS-IONOMER CEMENT}

GIC was developed in England by Wilson and Kent in $1972^{4}$ and introduced to the dental profession in 1988. ${ }^{5}$ The first generation of GIC includes water-based cements that were formed by an acid-base reaction between a calcium-based fluoroaluminosilicate glass powder and a polyalkenoic acid liquid. In later versions, calcium was replaced with strontium to impart radioopacity. ${ }^{6}$ It is interesting to note that because of their similarity in polarity and atomic size, these two elements are interchangeable in the composition of GIC as well as hydroxyapatite (HAP). The major attraction of GIC is its ability to chemically bond to dentine and enamel and to form an acid resistant interface $^{7}$ and the ensuing seal is both technique tolerant and long lasting, even under challenging clinical environment.

They have been described as bioactive materials due to the exchange of ions with tooth structures ${ }^{8}$ and can be thought of as a reservoir for fluoride and other ions in the oral cavity. ${ }^{9}$ This exchange is only possible because GICs contain both tightly and loosely bound water in its matrix, the set cement still contains between $11 \%$ to $24 \%$ of bound water. ${ }^{2}$ The liquid contains approximately $60 \%$ water by weight.

\section{THE SETTING REACTION}

The setting of GICs involves complex chemical reactions; in brief it can be separated into two distinct stages. Immediately after mixing, there is cross-linking of the poly-acid chains by either free calcium or strontium ions. The cross-linking during this stage is not stable and can be easily affected by excessive water loss or too much moisture contamination, due to poor isolation technique, during placement. During the second stage, the chains of polyacid are further cross-linked by trivalent aluminium ions. This later stage brings both an increase in mechanical properties, a reduction in solubility and improved aesthetic. Even at this stage the maintenance of water balance is still critical for the long-term clinical performance of the restoration. Indeed, the presence of some loosely bound water molecules in the solidified matrix is essential for ion exchange and recharging of fluoride ions. ${ }^{10-12}$

Fluoride is an essential part of the glass because it is used to control the fusion temperature and it is also a good oxide scavenger during the manufacturing of the glass. In the 

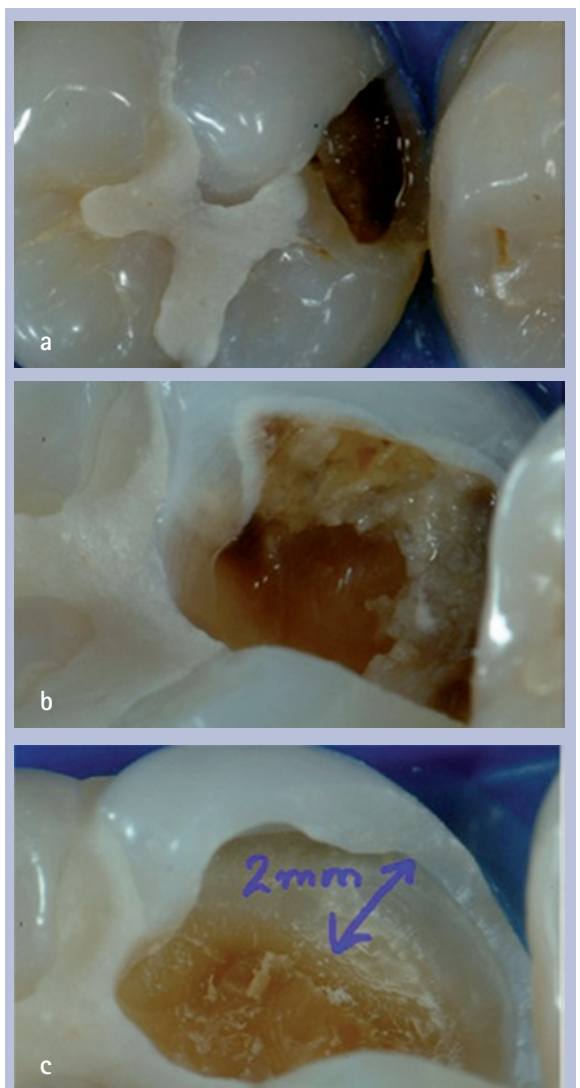

Fig. 1 The clinical application of the internal remineralisation concept is illustrated in this case. a) A patient presented with a proximal cavity and reported mild symptoms consistent with reversible pulpitis; b) Enamel removal to gain proper access to the cavity; c) Removal of carious dentine from the dentino-enamel junction, while the carious dentine from the pulpal and axial walls was left. A clean margin of two $\mathrm{mm}$ wide was created to ensure a long lasting seal, which is essential for the success of this therapy

set cement, fluoride does not form a physical part of the matrix so its release does not affect the physical property of the cement.

\section{TYPES OF GIC RESTORATIONS}

During its 30 year history, there have been a number of modifications to the original formulation with the aim to increase its physical properties, in particular wear resistance, reduce sensitivity to early water uptake so that restorations can now be placed and finished at the same visit and to enhance translucency to bring better aesthetic results. ${ }^{13}$

Today, GICs can be roughly divided into two groups: conventional and resin-modified. The first GICs introduced on the market are conventional, or auto-cured, GICs with self-adhesion to dentine and enamel. ${ }^{13}$ They provide a long lasting seal, which is due to their adhesion property and dimensional stability. However, these early GICs required careful maintenance of water balance immediately after placement.

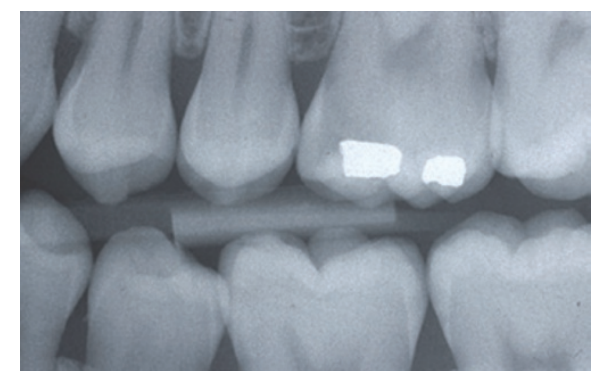

Fig. 2a Initial situation: the patient presented with a large proximal lesion and reported mild symptoms over a brief period

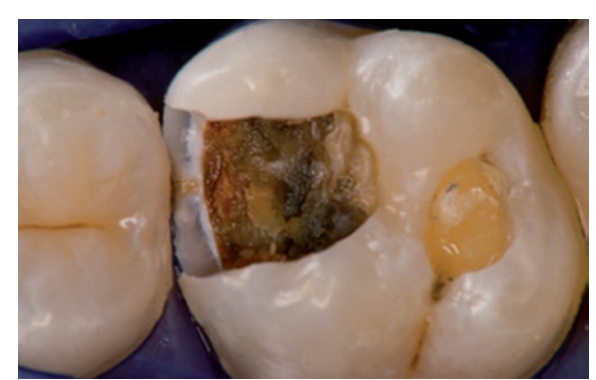

Fig. $2 b$ A clean margin of $2 \mathrm{~mm}$ wide was created using a round bur and only hand instruments were used to remove carious dentine, in order to minimise the risk of direct pulp exposure

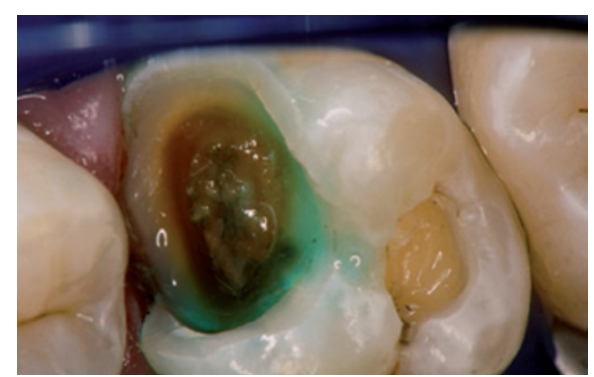

Fig. 2c The finished cavity was treated with $10 \%$ polyacrylic acid for ten seconds. Note that the enamel transverse ridge was retained so not to weaken the tooth crown

Due to lower physical properties, in comparison with composite resin, GICs should not be used where the restoration is exposed to excessive and repeated occlusal loads and where high level of aesthetics is required. Some conventional GICs are classified as high viscosity. These have good mechanical strength and, in particular, good wear resistance. ${ }^{13}$

The resin-modified-glass-ionomer cements (RMGIC) have similar components of conventional glass-ionomer cements plus a small quantity of resin hydroxyethylmethacrylate (HEMA) and bisphenol A glycidyl dimethacrylate (BisGMA) and both photo and chemical initiators. They set by the combined effects of photo and chemical polymerisation on top of the acid-base reaction. This means that these materials will eventually set completely even when there is inadequate light activation. It has been shown that their mechanical properties are not affected under these conditions. ${ }^{2,14}$

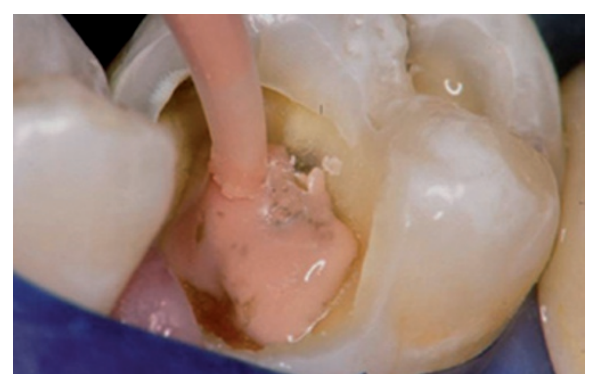

Fig. 2d A high fluoride-releasing GIC liner (Fuji Triage ${ }^{\circledR}$, GC Corporation) was applied over the discoloured dentine as a liner for internal remineralisation. A high-strength GIC was laid down, in particular over the dentinal margin (Fuji IX Extra, GC Corporation) as a base in preparation for the composite resin restoration

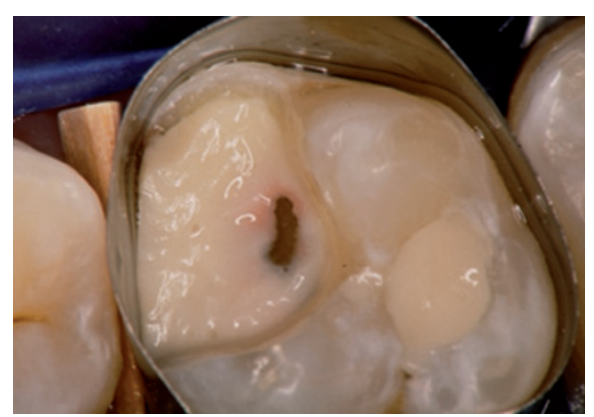

Fig. 2e Classical composite resin restoration

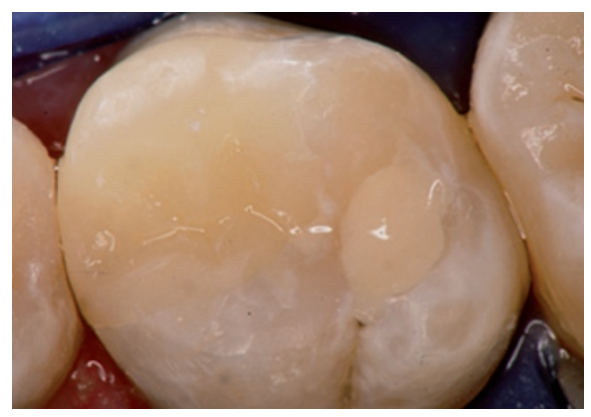

Fig. $2 f$ Final sandwich restoration

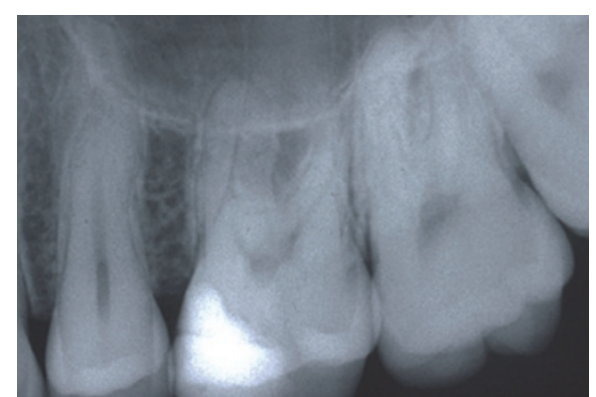

Fig. $2 \mathrm{~g}$ Radiograph of final restoration: partial excavation has preserved the integrity of the pulp

\section{BIOACTIVITY OF GIC}

Due to its ability to release and recharge of fluoride and exchange of strontium for calcium from its immediate environment (eg tooth structure, saliva and plaque fluid); GIC can be considered to be a reservoir of constituents of hydroxyl-apatite (eg fluoride, calcium/strontium and phosphate). ${ }^{15,16}$ It has been shown that the surface hardness 
of GIC can increase by 39\% over 40-day exposure to saliva. ${ }^{17}$

A major advantage of GIC is its ability to act as a fluoride reservoir in the oral cavity. The release of fluoride is characterised by a high initial peak, which decreases rapidly to maintain a sustained level over several months. ${ }^{18,19}$ However, there is a toppingup effect where GIC can be recharged with fluoride ions from external sources such as toothpastes, gels and varnishes. ${ }^{20}$ GIC restorations can be viewed as slow fluoride releasing devices. ${ }^{21}$ The caries preventive effect of GIC is restricted to its immediate vicinity, this protection has been observed not only along the margin of the restoration but also on proximal surface of the adjacent tooth. ${ }^{22,23}$

When GIC is placed in direct contact with caries affected dentine, the migration of apatite forming elements $\mathrm{F}$ and $\mathrm{Sr}$ from the GIC to carious dentine can be extensive. ${ }^{8}$

\section{DEEP CARIES}

GIC is an essential tool in the management of deep caries lesions in permanent teeth (codes 5 and 6 ICDAS II). Traditionally, we were taught that all soft and discoloured dentine at the base of these deep caries lesions should be completely removed in order to eradicate bacteria and to provide good supports for the overlying restoration. This approach often leads to the unnecessary removal of tooth tissue and mechanical pulp exposures. It was reported that in young patients the rate of pulp exposure can be as high as $40 \% .{ }^{24}$ In addition, it is now proven that the elimination of all microorganisms in the lesion is not at all possible. ${ }^{25}$

It is now well accepted that, when dealing with deep caries lesions on teeth, without any symptom of irreversible pulpitis, dentists should only selectively remove the infected layer and to leave the affected layer behind, so to avoid pulp exposure and to preserve pulp vitality. ${ }^{26,27}$ This approach is based on the work of Fusayama ${ }^{28}$ and Massler, ${ }^{29}$ which described the histology of these two layers of carious dentine. However, under clinical conditions, the differentiation of infected and affected dentine can be difficult, even with the aid of caries detector dyes. ${ }^{30,31}$ In 1992, Mertz-Fairhurst et al. confirmed, in a ten-year clinical trial, that any demineralised dentine left at the base of restorations did not continue to progress nor contribute significantly to the failure of the coronal restorations, as long as a seal was established and maintained..$^{32}$ More recently, systematic reviews have confirmed the above findings. ${ }^{33-36}$

As shown in the following case, most of the outer dentine was removed and a layer of softened dentine left at the base of the cavity; it is important to create a margin on sound dentin and enamel to ensure that a seal is achievable with the final restoration (Figs 1a-c). In the early version of this technique, step-wise excavation, a temporary restoration was placed and a time period of approximately six months was allowed for the deposition of tertiary dentine before replacing the temporary restoration with a final one. ${ }^{29}$ The current literature suggests that for most clinical cases the re-entry step can be eliminated, so a final restoration can be placed at the initial visit then the vitality of the tooth monitored..$^{27,37,38}$ The use of GIC is essential in this technique, because there is a suggestion that the demineralised dentine can be remineralised through an ion exchange process with GIC. This process was described as 'internal remineralisation' (Figs 2a-g). ${ }^{8,10}$ In addition, GIC can provide a long lasting seal through chemical adhesion that deprives the remaining bacteria of externally sourced nutrients. ${ }^{10}$ As GIC can be placed in proximity to the pulp without the risk of inducing inflammation, there is no need for the placement of any liner unless there is direct pulp exposure. ${ }^{38}$ It has been shown that this conservative approach is much kinder to the tooth, reducing the incidence of pulp exposure and ensuring a better prognosis. ${ }^{26,27,39,40}$

\section{THE SANDWICH TECHNIQUE}

Sandwich technique is a term that has been used to describe the use of GIC as a dentine replacement material or as a base in large posterior composite restorations. This technique can be further divided into either 'closed-sandwich', when the GIC is entirely enclosed within the composite restoration, or 'open-sandwich', when GIC is used as a base that is exposed to the oral cavity. ${ }^{41}$ The rationale for using a GIC base is to provide a seal at the gingival dentinal margin when enamel is missing and to reduce the depth of the proximal box so that light curing can be reliably achieved. It also reduces the number of increments of composite resin. ${ }^{42,43}$

\section{PIT AND FISSURE SEALANT AND PRE-FISSURE SEALANT}

GIC can be used as a pit and fissure sealant, the key advantage is that it offers a dual, mechanical and chemical protection with long-term fluoride release. However, it has been reported that its retention rate is lower than those achieved with resin based sealants. ${ }^{44-46}$ It is recommended where the tooth has not yet been fully erupted and moisture control is still difficult to achieve. ${ }^{47}$ The term pre-fissure-sealing is used to described the use of a high fluorine releasing GIC, such

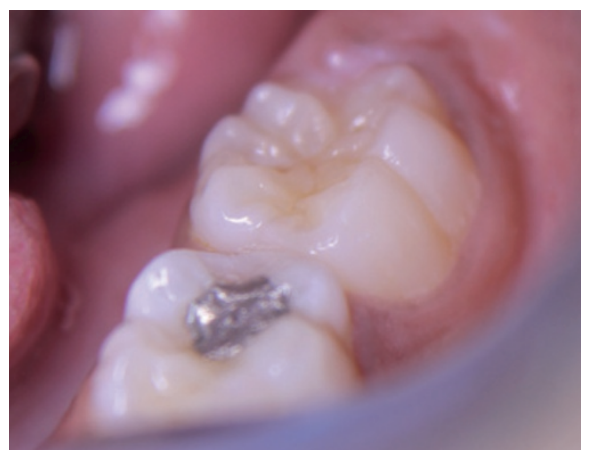

Fig. 3a Initial situation: erupting first permanent molar. Pre-fissure-sealant with GIC was recommended, because the tooth has not yet been fully erupted and moisture control is difficult to achieve

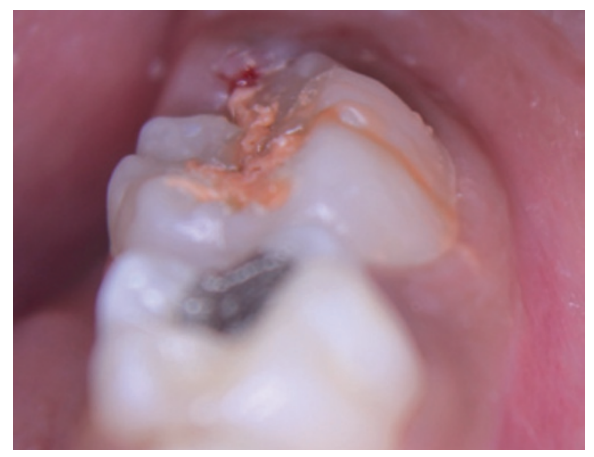

Fig. 3b A high fluoride-releasing GIC was chosen (Fuji Triage ${ }^{\circledR}$, GC Corporation)

as Fuji Triage (GC Corporation), to protect the occlusal surface of erupting permanent molars (Figs 3a and b). ${ }^{44,48,49}$

\section{PROTECTION OF ROOT SURFACES IN ELDERLY PATIENTS}

Root caries lesions are commonly found on exposed root surfaces in the elderly. These lesions are difficult to diagnose at an early stage because, unlike enamel lesions, the first changes are softening and surface roughening of the affected area, well before discolouration sets in. In addition, these early lesions are frequently masked by plaque and swelling of surrounding soft tissues and once established they often spread subgingivally. Bacteria can penetrate through the thin cementum into the underlying dentine very quickly. ${ }^{50}$ Root caries can be arrested with high fluoride and good oral hygiene; often it is difficult to satisfactorily restore these due to lack of access and adequate moisture control. GIC can be used to cover and protect the exposed root surfaces or to restore subgingival root caries lesion. Figure 4 presents a case of a patient with an original caries lesion that had been arrested for many years. This had been achieved with a combination of good oral hygiene, use of a high fluoridecontaining toothpaste, and daily application of a calcium and phosphate-containing paste to saturate the biofilm with minerals. The 
lesion displayed the three characteristics of a remineralised dentine surface; it was discoloured, shiny, and hard. However, with the onset of arthritis the task of keeping the area clean became too much of a challenge for the patient. After a period of assessment it was decided that the area should be protected with a thin therapeutic coat of high fluoride-releasing GIC, (Fuji Triage ${ }^{\infty}$, GC Corporation).

\section{CONCLUSIONS}

GIC plays an important role in both preventive and restorative dentistry. It can be considered as a reservoir of fluoride in the mouth. It can be used as a therapeutic coating to protect tooth surfaces against caries and contributes to the preservation of tooth structure by aiding the remineralisation process and providing a long-term seal.

The authors would like to thank Claudie DamourTerrasson, publishing director of the Groupe Information Dentaire, Paris, France, for the authorisation of translation and publication of the series in the BDJ; Drs Sophie Domejean and Avijit Banerjee for initiating and supporting this collaborative project.

1. Mickenautsch S, Mount G, Yengopal V. Therapeutic effect of glass-ionomers: an overview of evidence. Aust Dent J 2011; 56: 10-15.

2. Mount G J. An atlas of glass-ionomer cements: $a$ clinician's guide. 3rd ed. London: Martin Dunitz, 2002.

3. Tyas M J. Milestones in adhesion: glass-ionomer cements. J Adhes Dent 2003; 5: 259-266.

4. Wilson A D, Kent B E. A new translucent cement for dentistry. The glass ionomer cement. Br Dent J 1972; 132: 133-135.

5. Wilson A D, McLean J W. Glass ionomer cement. Chicago: Quintessence, 1988.

6. Wren A, Boyd D, Towler M R. The processing, mechanical properties and bioactivity of strontium based glass polyalkenoate cements. J Mater Sci Mater Med 2008; 19: 1737-1743.

7. Ngo H, Mount G J, Peters M C. A study of glassionomer cement and its interface with ename and dentin using a low-temperature, high-resolution scanning electron microscopic technique. Quintessence Int 1997; 28: 63-69.

8. Ngo H C, Mount G, Mc Intyre J, Tuisuva J, Von Doussa R J. Chemical exchange between glassionomer restorations and residual carious dentine in permanent molars: an in vivo study. J Dent 2006; 34: 608-613.

9. Ab-Ghani Z, Ngo H, McIntyre J. Effect of remineralization/demineralization cycles on mineral profiles of Fuji IX Fast in vitro using electron probe microanalysis. Aust Dent J 2007; 52: 276-281.

10. Ngo H. Glass-ionomer cements as restorative and preventive materials. Dent Clin North Am 2010; 54: 551-563.

11. Mount G. Glass-ionomer materials. In Hume W R, Mount $\mathrm{G} J$ (eds) Preservation and restoration of tooth structure. pp 163-197. Brighton: Knowledge, Books and Software, 2005.

12. Wilson D B. Properties of the entry and exit reactions of the beta-methyl galactoside transport system in Escherichia coli. J Bacterio/ 1976; 126: 1156-1165.

13. Attal J. Les ciments verres ionomères. In Matériaux alternatifs à l'amalgame. pp 12-20. Paris: ADF, 2002

14. Korkmaz Y, Ozel E, Attar N, Ozge Bicer C. Influence of different conditioning methods on the shear bond strength of novel light-curing nano-ionomer restorative to enamel and dentin. Lasers Med Sci 2010; 25: 861-866.

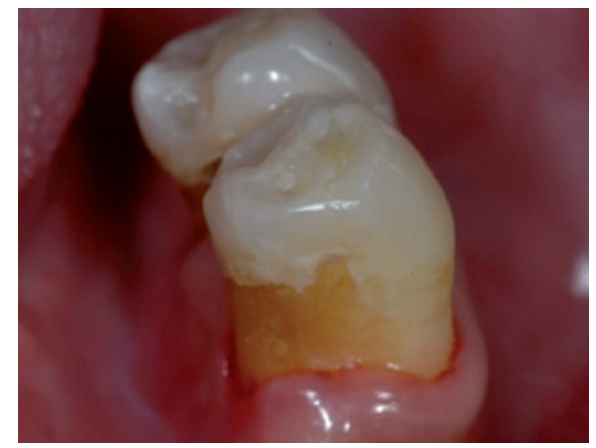

Fig. 4a Initial situation: the original caries lesion had been arrested for many years, but with the onset of arthritis the task of keeping the area clean became too much of a challenge for the patient. After a period of assessment it was decided that the area should be protected with a thin therapeutic coat of high fluoride-releasing GIC, (Fuji Triage ${ }^{\circledR}$, GC Corporation)

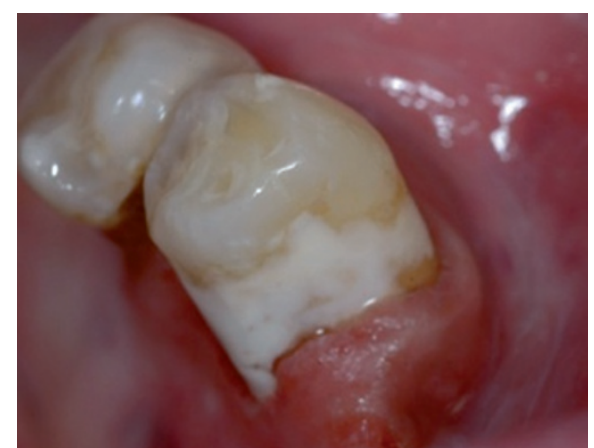

Fig. 4b Being a conventional GIC, this low viscosity GIC adheres well to the root surface and acts as a mechanical barrier to protect the area and minimise plaque accumulation. It releases significantly much more $F$ than the traditional restorative GICs and if recharged with fluoridated toothpaste then the $F$ release can be maintained indefinitely

15. Ngo H C, Mount G, Mclntyre J, Do L. An in vitro model for the study of chemical exchange between glass ionomer restorations and partially demineralized dentin using a minimally invasive restorative technique. J Dent 2011; 39(Suppl 2): S20-26.

16. Nicholson J W. Chemistry of glass-ionomer cements: a review. Biomaterials 1998; 19: 485-494.

17. Okada K, Tosaki S, Hirota K, Hume W R. Surface hardness change of restorative filling materials stored in saliva. Dent Mater 2001; 17: 34-39.

18. Gjorgievska E, Nicholson J W, Grcev A T. Ion migration from fluoride-releasing dental restorative materials into dental hard tissues. J Mater Sci Mater Med 2012; 23: 1811-1821.

19. Wiegand A, Buchalla W, Attin T. Review on fluoridereleasing restorative materials-fluoride release and uptake characteristics, antibacterial activity and influence on caries formation. Dent Mater 2007; 23: 343-362.

20. Cranfield M, Kuhn A T, Winter G B. Factors relating to the rate of fluoride-ion release from glass-ionomer cement. J Dent 1982; 10: 333-341.

21. Hengtrakool C, Pearson G J, Wilson M. Interaction between GIC and S. sanguis biofilms: antibacterial properties and changes of surface hardness. J Dent 2006; 34: 588-597.

22. Mickenautsch S, Yengopal V. Absence of carious lesions at margins of glass-ionomer cement and amalgam restorations: An update of systematic review evidence. BMC Res Notes 2011; 4: 58.

23. Yengopal V, Mickenautsch S. Caries-preventive effect of resin-modified glass-ionomer cement (RM-GIC) versus composite resin: a quantitative systematic review. Eur Arch Paediatr Dent 2011; 12: 5-14.

24. Leksell E, Ridell K, Cvek M, Mejare I. Pulp exposure after stepwise versus direct complete excavation of deep carious lesions in young posterior permanent teeth. Endod Dent Traumatol 1996; 12: 192-196.

25. Lager A, Thornqvist E, Ericson D. Cultivatable bacteria in dentine after caries excavation using rose-bur or carisolv. Caries Res 2003; 37: 206-211.

26. Bjorndal L, Reit C, Bruun G et al. Treatment of deep caries lesions in adults: randomized clinical trials comparing stepwise vs. direct complete excavation, and direct pulp capping vs. partial pulpotomy. Eur J Oral Sci 2010; 118: 290-297.

27. Ricketts D N, Kidd E A, Innes N, Clarkson J. Complete or ultraconservative removal of decayed tissue in unfilled teeth. Cochrane Database Syst Rev 2006; 3: CD003808.

28. Fusayama T, Okuse K, Hosoda H. Relationship between hardness, discoloration, and microbial invasion in carious dentin. J Dent Res 1966; 45: 1033-1046.

29. Massler M. Changing concepts in the treatment of carious lesions. Br Dent J 1967; 123: 547-548.

30. Anderson M H, Loesche W J, Charbeneau G T. Bacteriologic study of a basic fuchsin caries-disclosing dye. J Prosthet Dent 1985; 54: 51-55.

31. Kidd E A, Joyston-Bechal S, Beighton D. The use of a caries detector dye during cavity preparation: a microbiological assessment. Br Dent J 1993; 174: 245-248.

32. Mertz-Fairhurst E J, Curtis J W, Jr., Ergle J W Rueggeberg FA, Adair S M. Ultraconservative and cariostatic sealed restorations: results at year 10. J Am Dent Assoc 1998; 129: 55-66.

33. Kidd E A. How 'clean' must a cavity be before restoration? Caries Res 2004; 38: 305-313.

34. Alleman D S, Magne P. A systematic approach to deep caries removal end points: the peripheral seal concept in adhesive dentistry. Quintessence Int 2012; 43: 197-208.

35. Ferreira J M, Pinheiro S L, Sampaio F C, de Menezes $\checkmark \mathrm{A}$. Caries removal in primary teeth-a systematic review. Quintessence Int 2012; 43: E9-15.

36. Momoi Y, Hayashi M, Fujitani M et al. Clinical guidelines for treating caries in adults following a minimal intervention policy-evidence and consensus based report. J Dent 2012; 40: 95-105.

37. Maltz M, Oliveira E F, Fontanella V, Carminatti G. Deep caries lesions after incomplete dentine caries removal: 40-month follow-up study. Caries Res 2007; 41: 493-496.

38. Gruythuysen R J, van Strijp A J, Wu M K. Long-term survival of indirect pulp treatment performed in primary and permanent teeth with clinically diagnosed deep carious lesions. J Endod 2010; 36: 1490-1493.

39. Bjorndal L. Stepwise excavation may enhance pulp preservation in permanent teeth affected by dental caries. J Evid Based Dent Pract 2011; 11: 175-177.

40. Bjorndal L. Indirect pulp therapy and stepwise excavation. J Endod 2008; 34: S29-33.

41. Knibbs $P$ J. The clinical performance of a glass polyalkenoate (glass ionomer) cement used in a 'sandwich' technique with a composite resin to restore Class II cavities. Br Dent J 1992; 172: 103-107.

42. Andersson-Wenckert I E, van Dijken J W, Kieri C. Durability of extensive Class II open-sandwich restorations with a resin-modified glass ionomer cement after 6 years. Am J Dent 2004; 17: 43-50.

43. Andersson-Wenckert I E, van Dijken J W, Horstedt P. Modified Class II open sandwich restorations: evaluation of interfacial adaptation and influence of different restorative techniques. Eur J Oral Sci 2002; 110: $270-275$

44. Simonsen R J, Neal R C. A review of the clinical application and performance of pit and fissure sealants. Aust Dent J 2011; 56(Suppl 1): 45-58.

45. Kuhnisch J, Mansmann U, Heinrich-Weltzien R, Hickel R. Longevity of materials for pit and fissure sealing-results from a meta-analysis. Dent Mater 2012; 28: 298-303.

46. Beauchamp J, Caufield P W, Crall J J, Donly K J, Feigal R, Gooch B et al. Evidence-based clinical recommendations for the use of pit-and-fissure sealants: a report of the American Dental Association Council on Scientific Affairs. Dent Clin North Am 
2009; 53: 131-147.

47. HAS. Appréciation du risque carieux et indications du scellement prophylactique des sillons des premières et deuxièmes molaires permanentes chez les sujets de moins de 18 ans. 2005
48. Kamala B K, Hegde A M. Fuji III vs. Fuji VII glass ionomer sealants-a clinical study. J Clin Paediatr Dent 2008; 33: 29-33.

49. Bayrak S, Tunc E S, Aksoy A, Ertas E, Guvenc D, Ozer $S$. Fluoride release and recharge from different materials used as fissure sealants. Eur J Dent 2010; 4: $245-250$.

50. Lasfargues J J. Odontologie conservatrice et restauratrice. Tome 1: une approche médicale globale. 2010

\section{Erratum}

Letter (BDJ 2014; 216: 488-489)

'Oral surgery: ARONJ masterclass'

In the above letter, the author list should have read as follows:

A. Moore, S. Ruggiero, S. Rogers, T. Taylor, S. Popat, R. Coleman, S. Leyland, R. Popat, K. Sivardeen, I. Fogelman, A. Hawkesford and T. Renton

In the original letter the first author A. Moore was omitted in error.

We apologise for any confusion caused. 